\title{
Formation
}

Nordic Journal of Art and Research

ISSN: 1893-2479

wWw.artandresearch.info

\section{Skyvelære (While Attempting to Balance)}

\author{
Ellen Røed ${ }^{1}$ \\ Oslo and Akershus University College of Applied Sciences
}

\begin{abstract}
Visual artist, Ellen Røed, developed her practice by combining technological experimentation with images and an interest in how those images function in a performative context. As a research fellow in visual arts at Bergen Academy of Art and Design, from 2009-2013, Røed employed a variety of instruments to explore parallels and contradictions between video art and natural sciences, all centered on how we relate to our surroundings. In her own research, she interviewed scientific researchers as a basis for making art. She also experimented by using scientific instruments to create images. The result was a number of works that reflected on randomness, gestures, improvisation, and other informal aspects of formal knowledge. These works were shown in the Skyvelære exhibition at Gallery 3,14 in Bergen from June to August 2013. This text has been developed on the basis of material written at Bergen Academy of Art and Design on the occasion of the exhibition.
\end{abstract}

Keywords: art, video, gesture, standards, science, knowledge, performativity, rhythm, artistic research, Sarabande, International Pyrheliometer Comparison.

The video Skyvelare (While Attempting to Balance) portrays a specific scientific procedure, the calibration of instruments to the international standard for measuring solar irradiation. This procedure was carried out by eighty-five meteorologists and metrologists (scientific measurers) representing 45 countries at The 11th International Pyrheliometer Comparison Event (IPC-XI) and took place in Davos, Switzerland in September and October 2010. Skyvelare is a reflection on the informal aspects, such as gestures and performance, of the production of knowledge - seen in relationship to formal structures, such as rhythm and reference points. In the following paragraphs, I will provide an

\footnotetext{
${ }^{1}$ Department of Art, Design and Drama, Oslo and Akershus University College of Applied Sciences, PB 4, St. Olavs Plass, N-0130. E-mail: Ellen-Johanne.Roed@hioa.no
} 
Røed: Skyvelære

overview of the background for this piece, and what I wanted to explore in making it. I am primarily concerned with two things: the relationship between noise and form, and the relationship between formal knowledge and personal gesture.

In the video, images organized in a strict compostional pattern portray the movements of the scientists who are aligning and adjusting a variety of devices, all of them pointing towards the sun. The sound track is a non-discrete noise-like composition that evades perceptive categories and remains difficult to identify. It consists of a recording of a dancer's silk skirts, as she performs a Baroque dance in triple meter, the Sarabande. The rhythm and compostional structure of the Sarabande of Le Cinquième Suite, by Charles Dieupart, was used as principles for the editing of the video. When the video is exhibited in a gallery, the sound is spatialized as a movement that is present in the room.

During the Pyrheliometer Comparison Event, the days were divided into intervals of 90 minutes occurring repeatedly with six-minute breaks between them. These intervals were broken down into series 90-second segments, during which measurements were taken at 30-second intervals. When 85 people engage their bodies, especially their hands and eyes, in synchronized activities involving a variety of forms of the same type of instrument, complex rhythmic patterns occur. The mechanical beats of the instruments seemed to regulate the movement of the activities, while the slow steady pace of the earth's orbit around the sun was continually defining the direction, as the pyrheliometers were following and always pointing toward the sun, from dusk to dawn. The scientists embodied all of the different temporalities with elegance. As a means of exploring the aesthetic aspects of the relationship between formal and informal, along with a play of associations, I decided to incorporate a musical form that could be used to organize the informal movements into a structure with a distinct form. Modern scientific methods arose at approximately the same time as the dance Sarabande became popular at the French court. Originating in Guatemala and Mexico, the Sarabande was originally a noisy and erotic art form. The actual use of the word "sarabande" can be traced, via Spain, back to the Moors, when it is said to have meant "noise" in the Moorish language. Known to have been Louis XIV's favorite dance, it gradually became very slow and restrained, expressing desire through exquisite precision performed in an exaggerated manner. The Sarabande is characterized by solemnity and controlled passion. German music theorist Johann Mattheson even described it as being devoid of passion, merely expressing ambition (Mattheson, 1739).

It is not clear whether there are any real connections between Louis XIV, one of his favorite dances, and 85 meteorologists meeting on a mountain in Switzerland to measure the irradiance emitted by the sun. Nonetheless, by juxtaposing these elements, I reflected on this in the making of the piece that otherwise depicts the groundwork of the natural sciences, calibration. Fundamentally, I see calibration as a form of tuning. 
Røed: Skyvelære

As an artist, I have a direct, hands-on approach in my interactions with technological devices, such as cameras. A video camera is a prosthetic device that allows its user, me in this case, to capture and collect moving images from his or her surroundings. At the same time, the camera also serves as an evil mirror, constantly reminding its user that the world will always be beyond their reach. Hence, while I may appear to connect with it, I can never fully connect with what I am observing through the camera. Since that is precisely the gesture offered by the camera, there is an unremitting tension in the relationship I have with the images produced through the camera. Prior to making this video, I made pieces that explored the relationships between the landscape, the camera, and the recorded image. I was continually working with the camera, adjusting spatial relationships, or exploiting the limits of its technical conditions. Certain acts that can be considered forms of tuning, such as focusing, adjusting the aperture or shutter speed, as well as horizontal and vertical positioning, were significant in the resulting images. In that sense, as an artist, the activities involved in creating the representations generated a new level of understanding. Adjusting the devices seemed to allow technology, the environment, and me, as a human, to influence each other. In terms of video, the activities involved in collecting, observing, and processing imagery from the landscape offered a method for understanding it. This resonates with the work of early video artists such as Steina Vasulka, Nancy Holt, and Mary Lucier, who explored the camera by variously exploiting its capacities as a prosthesis, or as an autonomous device with its own electronic vision. In their work, the relationship between technology, image, and landscape was negotiated performatively, for example, when Mary Lucier let the sun burn a mark on the sensor of a camera, thus remaining present in/on all of the subsequent images that the camera produced.

Today, artists observe, listen to, and measure a variety of natural phenomena. Scientists, artists, art-scientists, experts, and non-experts, such as Andrea Polli, Roger Malina, and Erich Berger of the Finnish Bio Art Society, form communities to exchange the understanding that complements scientific knowledge on the natural environment. They engage in data gathering, collect sounds and images from the environment, take measurements, and collect samples from plants and animals. Among other, they map out pollutant levels, solar radiation, the movement of the stars in relation to satellites, and the relationship between the formation of algae and water temperature. Hitherto, until about a decade ago, similar inquiries in the field of art seemed to be an investigation of the digital: of the prosthetic characteristics of the devices, the data, and the networks. Artists were exploring what digital devices could do, how they generated meaning, and how they could be used. Today, as artists turn to considering aspects of understanding the environment through technology, such approaches seem different. Seminars, conferences, and festivals, such as the symposium In the Field, organized by CRISAP (Creative Research Into Sound Arts Practice) (CRISAP, 2013) frequently frame such 
practices as complementary to the natural sciences in terms of developing strategies as a way of producing cultural imaginaries, such as in Roger Malina's Intimate Science (Malina, 2010), or as having potential impact, as with the activities of Helsinki based Pixelache (Pixelache 2012). It is interesting to note that these approaches and discussions focus on the activities of getting the data from the environment, rather than on actually processing the data. This implies that the act of gathering data is, in itself, regarded as a means of creating insight. Related attitudes have been explored in video art, as well as through earlier artistic movements, such as through what is known as land art, and art and science. These perspectives in art consider artistic practice a form of inquiry, as a practice that leads to new insight. It seems relevant to consider certain aspects of this again, from a point in time where discussions of the relationships between art, research, and the natural environment are marked by a new urge, and by taking into account how certain tasks in the sciences, such as calibration, still require a hands-on approach. The personal, the experimental, and the informal produce insight, not least in terms of embodied performance. Although this insight is not quantified, verified, or disseminated through formal procedures as in science, it remains significant as a means of positioning and orienting oneself in the world.

Scientific engagement with measuring involves complex procedures for making data universally compatible, such as with IPC-XI, The 11th International Pyrheliometer Comparison Event. This constitutes a major difference between art and the natural sciences, at least in terms of how knowledge is verified. The use of international standards of reference is a cornerstone in such procedures. ${ }^{2}$ In referring to such standards, data are subsequently verified and agreed upon. In his work, 3 stoppages étalon (3 Standard Stoppages), 1913-1916, Marcel Duchamp created his own standard reference of a meter by dropping a thread onto a canvas. He stretched out his hands, one meter apart, and dropped the thread from a height of one meter. The thread was fixed as it fell. Using this method, Duchamp produced a measure that he later applied as a basic geometric unit, a meter. He repeated the procedure three times and produced three standard meters, all different and all equally valid. These were his standard meter, or étalon as it is called in French, and he used them as a measure in a number of his other artworks, including the seminal work La mariée mise à nu par ses célibataires, même (1913 - 1923) also known as "The Large Glass" (1915-1923). Standing as an iconic reference in the art field, this was a demonstration that, in art, standards can be experimental and random. Duchamp paved the way for an art that transcends subjective self-expression in favor of systematic consequent inquiries supported by procedures.

\footnotetext{
${ }^{2}$ The more famous such references include the kilo, the meter, and the volt. The kilo is still an actual object kept in a vault in Paris, while the meter has been replaced by an equation that defines a meter according to the speed of light. Today, there are more than 20,000 international standard references.
} 
Røed: Skyvelære

During IPC-XI, 85 meteorologists and metrologists from 45 different countries came together for three weeks at the Physikalisch-Meteorologisches Observatorium Davos/World Radiation Center to agree upon a joint standard reference for solar irradiance, and to calibrate their own nations' pyrheliometers in accordance with "the standard". A significant outcome of this conference was that the standard for solar measurements was verified and distributed throughout the international community. In scientific terms, this procedure is merely maintenance, a formality. Nonetheless, while in itself it does not produce any new knowledge, it ensures the premises for objective scientific knowledge production. Duchamp's etalon however, was not merely random, it was also personal, and a direct result of the movement of his hands. When he used it as a formal reference, a geometric unit, he demonstrated that, in terms of procedure, his gesture was as good as any other measure. Then he dropped another thread - and yet another. In the end, Duchamp had the results of three gestures, three experiments; for him, they were all equally valid, both as a reference and as a measure.

As with the outcome of IPC-XI, Duchamp's standard is a convention that makes data comparable. The work is remarkably precise and compact in its critique of science. It is both in favor of and in a critique of scientific methods. Critical of the emphasis on visual appearance and artistic self-expression in the arts, Duchamp was clearly disappointed with the determinism that frequently defines art as a creative medium. He was in an early phase of developing an aesthetic that moves toward early ideas of systems/parameters/logic and mechanisms of transformation; this homage to gesture complements the systematic and the mechanical with the personal and the random.

As Henri Poincaré proposed in 1902, internationally approved scientific standards are not representations of an absolute truth, they are based on conventions. Nonetheless, they are based on conventions. Such conventions are the result of long international processes that are followed by a continually occurring calibration procedure to ensure that they are distributed throughout the entire community. Calibration can be seen as a kind of tuning, a preparation of an instrument, which ensures that it will perform well within a larger context. As a means of ensuring that all of the gathered data are comparable, within the practices of scientific and commercial measurements, calibration also means tuning the instruments according to this shared point of reference. Certain contemporary philosophers of science, such as Roger Strand at the University of Bergen (Strand, 2002), seem to be acknowledging that contemporary governance might require that knowledge is verified in a less formal manner, and rather be approved by alternative procedures. In my own work, the informal gestures perceived at the data gathering event becomes significant through the way they are organized in a rhythmic structure. As he holds his thumb up toward the sky to see whether it can cover the sun or not, the gesture performed by a Chilean meteorologist becomes significant as another meteorologist, wearing the same hat, repeats the movement in almost exactly the same way. While performing a 
Røed: Skyvelære

ritual, they are tuning in with the world, positioning their body in relationship to the sun, to their technology, and to their community.

Calibration events can last for weeks. In the meantime, completely random incidences happening elsewhere, such as an invisible stream of sand being sucked into the atmosphere during a storm in the Sahara Desert, can block the path between the sun and 85 meteorologists and metrologists who have gathered on a mountain in Switzerland to calibrate their instruments. This storm in the Sahara can destroy their data and render their measurements useless. I presume that this arbitrary and performative nature of knowledge is what Duchamp was trying to make us understand when using gesture to produce a standard, as he did in 1913. Nonetheless, by applying his arbitrary gestures systematically, he renders them as a formal procedure, which transcends the random and offers a new map, a structure, and perhaps a grammar for knowing where to position things in relationship to each other. It is at this point that he knows where things should go. Indeed, there is a connection and all he has to do is tune in.

\section{On the contributor}

Ellen Røed's practice as a visual artist has developed through specific technological experimentation with images, mixed with an interest in how images function in a performative context. As a research fellow in visual arts at Bergen Academy of Art and Design, from 2009-2013, Røed explored parallels and contradictions between video art and natural sciences, based on how we relate to our surroundings by employing various instruments. In her research, Røed interviewed scientific researchers as a basis for making art. She also experimented by using scientific instruments to make images. The result was a number of works that reflected on randomness, gestures, improvisation, and other informal aspects of formal knowledge, shown in the exhibition Skyvelaere at Gallery 3,14 in Bergen from June to August 2013.

\section{References:}

CRISAP. (2013). In the Field. From http://www.inthefield.org.uk/

Malina, Roger. (2010) Intimate Science and Hard Humanities: A Call for Open Observatories, From http://malina.diatrope.com/2010/03/16/intimate-science-and-hard-humanities-a-call-for-openobservatories/ Accessed on 2013-01-13.

Mattheson, J. (1739). Der vollkommene Capellmeister. Hamburg: Christian Herold.

Pixelache (2012). http://www.pixelache.ac/helsinki/pixelversity/programme-2012/environment/ Accessed on 2013-01-13.

Strand, R. (2002). Complexity, Ideology, and Governance. Emergence, 164 - 183. 